\title{
MAZZUCCHELLI, FREDERICO. OS ANOS DE CHUMBO: ECONOMIA E POLÍTICA INTERNACIONAL NO ENTREGUERRAS. CAMPINAS: UNESP-FACAMP, 2009. 429 p.*
}

\section{Rogério Arthmar}

Em vista da dimensão da crise financeira da atualidade, não poderia ser publicado em momento mais oportuno o livro do Professor Frederico Mazzucchelli, Os anos de chumbo: economia e política internacional no entreguerras. O título, por si, informa de antemão que o conteúdo privilegia não apenas a instância estritamente econômica, mas também a política, pois nessa esfera, tanto em nível doméstico quanto na arena diplomática mundial, sucederiam eventos decisivos que culminariam nos dois maiores enfrentamentos bélicos da humanidade. A obra contém dez ensaios sobre temas fundamentais da metade inicial do século XX, ressaltando a precariedade do arranjo estrutural vivenciado pela economia internacional no pós-Primeira Guerra Mundial. Embora o prefácio mencione a possibilidade de leitura isolada dos capítulos, resulta impraticável ao interessado deixar de lado uma única página do livro em vista da relevância dos assuntos selecionados.

Dois aspectos de Os anos de chumbo lhe conferem consistência singular. Inicialmente, a preocupação do autor em reconstituir, já no Capítulo 1, os antecedentes históricos da economia internacional durante o século XIX. Esse é o tempo em que a Inglaterra assume a condição de maior potência industrial do planeta, o liberalismo passa a reger sua política interna, consolidam-se os impérios coloniais europeus e o sistema de padrão-ouro alcança abrangência máxima. Nas décadas finais dessa era de expansão, os Estados Unidos e a Alemanha firmam-se igualmente como economias de industrialização retardatária, porém de vanguarda em termos tecnológicos, gerenciais e de escala de produção, fenômeno com impacto de largo alcance no século seguinte, notadamente no acirramento da concorrência entre as potências europeias nos anos anteriores a 1914: "A competição pelo poder entre as nações, a exacerbação do nacionalismo e a rigidez do sistema de alianças revelavam a precariedade do equilíbrio internacional" (Mazzucchelli, 2009, p. 48).

\footnotetext{
* Texto recebido em 03/04/2012 e aprovado em 18/04/2012.

${ }^{1}$ Doutor em Economia pela FEA-USP e professor associado do Departamento de Economia e do Mestrado em Economia da Universidade Federal do Espírito Santo. Contato: arthmar@npd.ufes.br.
} 
No Capítulo 2 são apresentados os fatores determinantes para a Primeira Guerra, seus efeitos econômicos e geopolíticos na nova conformação do espaço europeu, bem como a fragilidade do concerto internacional divisado pelos governantes Aliados em Versalhes. Os Capítulos 3 e 4 reconstroem os dilemas políticos, financeiros e econômicos de Inglaterra e França em sua dura jornada em favor da retomada e, posteriormente, do abandono do padrão-ouro, decidido sob o impacto devastador da Grande Depressão. Os Capítulos 5 e 8 tratam da economia alemã, cobrindo da República de Weimar ao domínio nazista, com destaque ao explosivo problema das reparações e, adiante, à política anticíclica de Adolf Hitler, apoiada na compressão do consumo, na centralização cambial e na expansão do investimento público, o qual viria a privilegiar o rearmamento nacional após o II Plano Quadrienal de 1936.

Nos Capítulos 6 e 7 são examinadas as flutuações econômicas nos Estados Unidos no intervalo, análise precedida por importante panorama da portentosa expansão industrial do país depois da Guerra da Secessão. Mazzucchelli discute o envolvimento do colosso norte-americano na Primeira Guerra Mundial, a recessão de 1920-1921, a expansão de 1923-1929 (the roaring twenties) e, por fim, a Grande Depressão. A causa maior da crise deflagrada em 1929, segundo ele, teria residido na profunda reversão das expectativas otimistas dos investidores, ocasionada pela débâcle da valorização financeira do capital em Wall Street e agravada, em seguida, pela desorganização do sistema bancário do país. O New Deal recebe atenção especial do autor, que traça em detalhes os desdobramentos da nova visão administrativa do governo comandado pelo Presidente Franklin D. Roosevelt no tocante à regulação do sistema financeiro, ao apoio à agricultura, à política industrial de promoção da concorrência e, por fim, à promulgação de leis inéditas voltadas ao estabelecimento do novo estado de bem-estar.

Os Capítulos 9 e 10 são dedicados à apresentação dos antecedentes políticos e ao escrutínio, não apenas das implicações econômicas, mas também do calamitoso impacto humano da Segunda Guerra Mundial. "Os combates militares, os bombardeios as execuções, o extermínio dos povos, a fome, as doenças, os campos de concentração, os trabalhos forçados, as fugas e os deslocamentos resultaram na morte de cerca de 37 milhões de pessoas, tão somente na Europa" (Mazzucchelli, 2009, p. 344). Em contraste com esse cenário sombrio, ao final do capítulo é realçado o ambiente de paz e de reconstrução possibilitado pela materialização da hegemonia econômica e militar dos Estados Unidos, condição indispensável para o progresso de um capitalismo internacional regulado, doravante, pelos Estados nacionais: "O aspecto mais relevante é que, por quase três décadas, em meio às tensões e rusgas da Guerra Fria - $e$, sobretudo com memória viva do passado - o capitalismo demonstrou enorme capacidade de crescimento em termos mundiais" (Mazzucchelli, 2009, p. 419, itálicos no original).

Uma segunda característica da obra a ser salientada diz respeito à preocupação do autor em reconstituir os principais indicadores econômicos dos países estudados, 
respaldando nas séries de produção, de preços e das contas externas, entre outras, a análise dos fatos contemplados no livro. Apesar da fragilidade inevitável de alguns números em virtude da prática pouco comum de mensuração dos agregados econômicos nos anos em tela, o procedimento é essencial para deslindar as tendências estruturais daquele tempo, permitindo o confronto inevitável entre certas teses sobre os fenômenos de então, discutidas ao longo dos capítulos, e os dados correspondentes. A utilidade de tal opção metodológica revela-se, por exemplo, na seção dedicada às causas da hiperinflação alemã, quando o pagamento das reparações, comumente responsabilizado pela depreciação do marco entre 1919 e 1923, tem sua culpa expiada por conta da constatação de que, até o advento do Plano Dawes, a Alemanha de fato transferira valores reduzidos nesta rubrica, tanto em moedas fortes quanto em matérias-primas e carvão. Crucial, no processo de derrocada do câmbio, conforme Mazzucchelli, teria sido a fragilidade estrutural da economia germânica no pós-guerra, motivo último da evasão de capitais: "A moeda, como sabemos, é acima de tudo uma convenção fundada na confiança. E era exatamente a confiança que faltava à Alemanha nos anos que se seguiram ao final do conflito" (2009, p. 147).

A combinação entre a história e as estatísticas ajuda a explicar, igualmente, um dos eventos centrais da época: o retorno da Inglaterra ao padrão-ouro na antiga cotação de U $\$ 4,86$ dólares por libra esterlina. A decisão impôs imenso ônus ao país, uma vez que a moeda britânica encontrava-se sobrevalorizada em relação ao dólar devido à inflação de guerra, impondo grande dificuldade à indispensável expansão das exportações nacionais e ampliando o déficit comercial de $£ 153$ milhões em 1913 para uma média de $£ 398$ milhões entre 1924-1929. Ocorre, entretanto, que o balanço de pagamentos da Inglaterra, às vésperas do conflito, era largamente superavitário nas transações invisíveis, ou seja, nos seguros e comissões, nos fretes marítimos e nos lucros e dividendos recebidos dos capitais acumulados no exterior, perfazendo tudo isso $£ 346$ milhões em 1913, valor suficiente para cobrir inclusive a totalidade das novas exportações de capitais (Deane e Cole, 1969, p. 36-38). Ou seja, a economia britânica se transformara em uma nação rentista, na qual as considerações das indústrias tradicionais (têxteis, mineração, ferro e aço e transportes) encontravam-se subordinadas aos interesses financeiros.

Do ponto de vista histórico, após o intervalo de restrição nos pagamentos em espécie durante as Guerras Napoleônicas (1797-1815), a Inglaterra atravessou forte processo deflacionário e retomou a conversibilidade plena da moeda em 1821, medida que concorreria para consolidar a liderança financeira britânica no contexto mundial durante o século XIX (Fetter, 1965, caps. II-IV). Mazzucchelli destaca este aspecto com clareza:

Entre 1870 e 1890, a preeminência de Londres como centro financeiro internacional era indiscutível: quer no financiamento do comércio internacional, quer nos empréstimos 
aos países, quer na gestão do padrão monetário internacional - cuja cúspide era o Banco da Inglaterra - era Lombard Street que coordenava as finanças internacionais. (Mazzucchelli, 2009, p. 42)

Não fosse isso o bastante, o Diretor Geral do Banco da Inglaterra, Montagu Norman, temia que a demora do país em restabelecer a cotação do pré-guerra abrisse espaço irreversível ao dólar como nova moeda de referência universal dos negócios. Devido a isso, os representantes da instituição buscaram dominar a seção financeira da Liga das Nações, encarregada da reconstrução de diversas economias europeias, como forma de amarrar as novas moedas nacionais à libra, para inconformismo dos franceses (Orde, 1990, p. 299-315; Péteri, 1992). Ou seja, não faltavam razões à Inglaterra para retornar ao padrão-ouro, constituindo matéria de debate apenas a data e a taxa de câmbio mais convenientes para tanto ${ }^{2}$.

A importância do conteúdo tratado em Os anos de chumbo enseja alguns comentários adicionais a propósito da interpretação do autor sobre determinados eventos contemplados no correr da obra. A avaliação negativa do desempenho econômico da França no período, julgada uma "nau sem rumo", deve seguramente ser atenuada, em particular no que se refere à estratégia francesa para o problema das reparações, qualificada como "descabida" e "tosca" (Mazzucchelli, 2009, p. 95). A França, cumpre assinalar, enfrentava situação extremamente delicada durante o pós-guerra. Como registrado na abertura do terceiro capítulo do livro, a destruição material e as perdas humanas da nação francesa, principal palco do conflito no front ocidental, foram imensas, enquanto a Alemanha, não obstante as defecções territoriais e as baixas nos campos de batalha, permaneceu com a sua capacidade produtiva industrial praticamente intocada ${ }^{3}$. Além disso, o alto comando alemão concebia a frustrada ofensiva de 1818 como indispensável à ocupação da Bélgica e à incorporação de territórios essenciais às investidas futuras do Império Germânico. "Se a Alemanha alcançar a

\footnotetext{
${ }^{2}$ A discordância de Keynes com a decisão de Churchill se localizava justamente neste último ponto, pois a retomada da paridade do pré-guerra haveria resultado em sobrevalorização da libra, com o aprofundamento do déficit comercial, a necessidade de juros elevados para a atração de capitais, a redução do investimento interno e o consequente agravamento do desemprego. Keynes, porém, não ousou recomendar o abandono da conversibilidade, propondo unicamente uma política de crédito fácil e a transferência de ouro para os Estados Unidos como forma de elevar os preços norte-americanos (Keynes, [1931] 1970).

3 "Ao final das hostilidades, a produção industrial na França encontrava-se em nível muito reduzido. Isso era de se esperar. As principais plantas industriais do país, situadas no norte devastado, haviam sido danificadas ou destruídas. Os mercados nacionais estavam em estado caótico [...] A moeda era instável; a mão-de-obra encontrava-se insatisfeita" (Ogburn e Jaffé, 1929, p. 93). A contabilidade da tragédia foi alarmante: 1,3 milhões de mortos por fogo inimigo, 2,8 milhões de feridos, 600 mil inválidos e 60 mil amputados; 564 mil usinas, prédios e edificações destruídos ou danificados, 3,2 milhões de hectares arruinados, a produção de carvão reduzida em 36\%, a de aço em 61\% e a de cereais em 40\%, comparando-se 1919 com 1913 (Chastenet, 1970, p. 15-17).
} 
paz sem conquistas, ela haverá perdido a guerra”, declarou o general Erich Ludendorff em fevereiro daquele ano (Koeltz, 1927, p. 160). Ou seja, a perspectiva de nova conflagração já era admitida nos altos escalões militares alemães mesmo na hipótese de vitória sobre os Aliados. Para os políticos franceses, configurava-se, portanto, questão vital reerguer o país, retardar o avanço da Alemanha e preservar a todo custo a aliança com a Inglaterra e os Estados Unidos como penhor da soberania nacional.

Apesar do rodízio constante no cargo de premier, especialmente na década de 1920, dois nomes dominaram a cena política francesa naqueles anos, Aristide Briand (1862-1932) e Raymond Poincaré (1860-1934) (Yvert, 2002, p. 409-423 e p. 431-435). O primeiro chefiou o maior número de gabinetes na história do país, tendo, além disso, assumido diversas vezes a pasta dos Assuntos Estrangeiros, marcando a sua atuação diplomática junto à Alemanha como um apaziguador e revisionista, circunstância que, frequentemente, lhe rendeu a oposição ferrenha da direita nacionalista do Bloc National ${ }^{4}$. Ciente da fragilidade francesa, procurou estabelecer um entendimento pessoal com o primeiro-ministro alemão e, após, chanceler, Gustav Stresemann, a fim de mitigar as tensões permanentes entre os respectivos povos, levando os germânicos à Liga das Nações e tendo sido, inclusive, um dos pioneiros na proposta de aprofundamento da integração política e econômica europeia 5 . Quanto a Poincaré, há que se levar em conta as condições dificílimas que cercaram sua decisão de invadir o Ruhr. Os indispensáveis carregamentos de carvão para o suprimento da indústria francesa escassearam no ano de 1923, enquanto os alemães requisitavam moratória de todos os tipos de transferências até 1924. Além disso, o primeiro pagamento efetivo de reparações à França fora inteiramente repassado à Bélgica e daí destinado a amortizar os empréstimos de guerra junto aos ingleses. A questão toda, de resto, girava em torno de um impasse quase insuperável: a Alemanha só poderia honrar os pagamentos à França com créditos dos bancos norte-americanos que, por sua vez, exigiam redução no montante das reparações. Mas a França não dispunha de margem de manobra para tanto sem diminuição correspondente nos débitos aliados, recusada liminarmente pelo governo norte-americano. Ao aceitar, com as tropas francesas em solo alemão e

\footnotetext{
${ }^{4}$ O prêmio Nobel da Paz foi concedido a Briand e Stresemann, em 1926, devido à assinatura do Pacto de Locarno no ano anterior, garantindo as fronteiras europeias definidas pelo Tratado de Versalhes. $\mathrm{O}$ político francês não compareceu à cerimônia, mas comunicou por seu representante: "Nenhum reconhecimento pode ser mais precioso para mim do que este que agora coroa o esforço mais importante de minha vida pública, ao qual me dediquei com todas as forças, a promoção do seu [Comitê Nobel] ideal de paz" (Briand, 1926).

5 "Encontrar-nos-emos, em pouco tempo, cercados por duas potências formidáveis, os Estados Unidos e a Rússia. Você pode ver muito bem a necessidade de constituição dos Estados Unidos da Europa", declarou Briand ao seu colaborador no Quai d'Orsay, Jules Laroche, durante a Conferência de Cannes em 1922 (Chastenet, 1970, p. 111).
} 
um mês após a capitulação do governo em Berlim, que as reparações fossem definidas pelo Comitê Dawes, o que significava corte substancial no valor devido total, Poincaré mostrou-se, em verdade, um moderado entre seus incendiários companheiros da maioria parlamentar (Bonnefous, 1968, p. 388-396; Maier, 1988, p. 387-414) ${ }^{6}$. A intolerância perante o tema das reparações, se descreve corretamente a atitude de parte considerável da nação francesa à época, não pode ser atribuída, contudo, sem as qualificações necessárias, às principais lideranças do país nos anos de 1920.

Ainda, no Capitulo 7, dedicado ao New Deal, é descartada a conhecida tese de Peter Temin de que a desvalorização do dólar realizada em 1933 haveria sinalizado mudança radical de regime, com o potencial se indicar aos agentes privados a adoção de uma nova política econômica expansionista e inflacionária (Temin e Wigmore, 1990). De acordo com Mazzucchelli:

O argumento de Temin supõe um nível de clareza e de coerência programática que nem Roosevelt nem os new dealers tinham, ou sequer podiam ter. Supõe, ademais, um grau de coesão política e de confiança na comunidade de negócios nos rumos da administração democrática, que sempre esteve longe de existir. (Mazzucchelli, 2009, p. 230)

A afirmação se afigura correta no seu aspecto histórico, mas o argumento de Temin é, mais propriamente, uma tentativa de elucidar a reversão do ciclo em curto prazo, ou seja, de mostrar porque a depressão deixou de se aprofundar nos Estados Unidos após a posse de Roosevelt. Em versão mais recente, Eichengreen e Temin (2000) sustentam, em tom menos dramático, que a desvalorização teria representado o abandono das regras rígidas do padrão-ouro, inviabilizadas pela ascensão das massas ao processo eleitoral, abrindo assim espaço crítico para políticas anticíclicas que priorizavam a economia doméstica em vez da paridade da moeda.

No que respeita ao final da Grande Depressão, Mazzucchelli minimiza o papel dos investimentos privados e atribui a recuperação da economia norte-americana, verificada em 1934-1937, à combinação de uma série de fatores, entre eles a ampliação dos gastos públicos, o crescimento real dos salários, a elevação da renda agrícola, a redução nas taxas de juros, a estabilização do sistema bancário e o abandono explícito das políticas deflacionárias do padrão-ouro (Mazzucchelli, 2009, p. 232). Nesse rol, contudo, pode ser incluído um fator adicional. Até mesmo os estudos mais recentes, ressaltando a importância da política fiscal de Roosevelt em reorientar a economia para uma nova fase expansiva, reconhecem que o estímulo, apesar de sua importância, foi insuficiente

\footnotetext{
${ }^{6}$ Moderação semelhante seria evidenciada novamente por Poincaré no ano de 1926, durante o processo de estabilização da moeda quando, perante a insistência do diretor geral do Banco do França, Emile Moreau, aceitou, contra a sua vontade pessoal, uma desvalorização de $80 \%$ na cotação do franco (Blancheton, 2001, p. 383-414).
} 
para responder pela totalidade do processo ${ }^{7}$. Embora a razão entre o consumo e o investimento privado tenha declinado no intervalo, de acordo com Mazzucchelli, os dados por ele compilados mostram que entre o fundo da Grande Depressão, em 1933, e o auge da retomada, em 1937, o consumo pessoal cresceu em média 6,5\% ao ano, enquanto a formação de capital se expandiu a uma taxa aproximadamente quatro vezes superior, com média anual de 24,5\% (Mazzucchelli, 2009, p. 233, Tabela 7.1). O crescimento da oferta monetária na economia norte-americana após 1933, motivado pelo elevado influxo de ouro do exterior, como observou Christina Romer (1992), permitiu, de uma parte, queda nas taxas de juros nominais, e de outra recuperação dos preços, resultando em taxas de juros reais negativas no período e alta progressiva do consumo de bens duráveis e do investimento doméstico bruto.

Por fim, merece congratulações o empenho do autor de Os anos de chumbo em oferecer ao público análise criteriosa dos eventos de um recorte único da história contemporânea, quando os destinos da humanidade se forjaram no fogo inclemente dos canhões. Ao se debruçarem sobre a obra, as novas gerações de economistas poderão remontar ao século XX e testemunhar como as nações industriais, em um tempo ainda vivo na memória de muitos, enfrentaram desafios de magnitude sem par até os dias de hoje. As lições daquele período, como a crise atual insiste em mostrar, necessitam ser revistas com urgência. O livro do Professor Mazzucchelli atende ao chamado e anuncia a todos: - Presente!

\section{REFERÊNCIAS}

BLANCHETON, B. Le Pape et l'Empereur. La Banque de France, la direction du Trésor et la politique monétaire de la France (1914-1928). Paris: Albin Michel, 2001.

BONNEFOUS, É. Histoire politique de la Troisième République. Tome III. Laprés-Guerre (1919-1924). Paris: Presses Universitaires de France, 1968.

BRIAND, A. Acceptance speech: The Nobel Peace Prize 1926 (telegram). Disponível em <http:// www.nobelprize.org/nobel_prizes/peace/laureates/1926/briand.html>. Acesso em 30 de março de 2012.

CHASTENET, J. Les années d'illusions 1918-1934. Cent ans de République. Tome Cinquième. Paris: Jules Talandier, 1970.

DEANE, P.; COLE, W.A. British economic growth 1688-1959. Cambridge: Cambridge University Press, 1969.

\footnotetext{
7 “O problema com os déficits anteriores à recessão de 1937-1938 não reside no fato de terem sido involuntários, o que é correto, mas na circunstância de não terem sido eles suficientemente amplos para a tarefa. A política fiscal não falhou; ela apenas não foi tentada de maneira adequada" (Perry e Vernengo, 2011, p. 15).
} 
EICHENGREEN, B.; TEMIN, P. The gold standard and the Great Depression. Contemporary History Review, v. 9, n. 2, p. 183-207, 2000.

FETTER, F.W. Development of British monetary orthodoxy 1797-1875. Cambridge: Harvard University Press, 1965.

KEYNES, J.M. The economic consequences of Mr. Churchill. In: POLLARD, S. (ed.) The gold standard and employment policies between the wars. London: Methuen, p. 28-43, 1970.

KOELTZ, L. Les causes de l'effondrement militaire allemand en 1818. Revue d'Historie de La Guerre Mondiale, ano 5, n. 1, p. 129-161, 1927.

MAIER, C.S. Recasting bourgeois Europe. Stabilization in France, Germany and Italy in the decade after World War I. Princeton: Princeton University Press, 1988.

OGBURN, W.F.; JAFFÉ, W. The economic development of post-war France. A survey of production. New York: Columbia University Press, 1929.

ORDE, A. British policy and European reconstruction after the First World War. Cambridge: Cambridge University Press, 1990.

PERRY, N.; VERNENGO, M. What ended the Great Depression? Reevaluating the role of fiscal policy. Levy Economics Institute, Working Paper, p. 678, 2011.

PÉTERI, G. Central bank diplomacy: Montagu Norman and Central Europe's monetary reconstruction after World War I. Contemporary European History, v. 1, n. 3, p. 233-258, Nov. 1992.

ROMER, C.D. What ended the Great Depression? The Journal of Economic History, v. 52, n. 4, p. 757-784, Dec. 1992.

TEMIN, P.; WIGMORE, B. A. The end of one big deflation. Explorations in Economic History, n. 27, p. 483-502, 1990.

YVERT, B. Premiers ministres et presidents $d u$ Conseil depuis 1815. Histoire et dictionnaire raisonné des chefs du gouvernement en France (1815-2007). Paris: Perrin, 2002. 